\title{
Regional hydrological impacts of climate change: implications for water management in India
}

\author{
ARPITA MONDAL ${ }^{1}$ \& P.P. MUJUMDAR ${ }^{1,2}$ \\ 1 Department of Civil Engineering, Indian Institute of Science, Bangalore 560012, India \\ 2 Divecha Center for Climate Change, Indian Institute of Science, Bangalore 560012, India \\ pradeep@civil.iisc.ernet.in
}

\begin{abstract}
Climate change is most likely to introduce an additional stress to already stressed water systems in developing countries. Climate change is inherently linked with the hydrological cycle and is expected to cause significant alterations in regional water resources systems necessitating measures for adaptation and mitigation. Increasing temperatures, for example, are likely to change precipitation patterns resulting in alterations of regional water availability, evapotranspirative water demand of crops and vegetation, extremes of floods and droughts, and water quality. A comprehensive assessment of regional hydrological impacts of climate change is thus necessary. Global climate model simulations provide future projections of the climate system taking into consideration changes in external forcings, such as atmospheric carbon-dioxide and aerosols, especially those resulting from anthropogenic emissions. However, such simulations are typically run at a coarse scale, and are not equipped to reproduce regional hydrological processes. This paper summarizes recent research on the assessment of climate change impacts on regional hydrology, addressing the scale and physical processes mismatch issues. Particular attention is given to changes in water availability, irrigation demands and water quality. This paper also includes description of the methodologies developed to address uncertainties in the projections resulting from incomplete knowledge about future evolution of the human-induced emissions and from using multiple climate models. Approaches for investigating possible causes of historically observed changes in regional hydrological variables are also discussed. Illustrations of all the above-mentioned methods are provided for Indian regions with a view to specifically aiding water management in India.
\end{abstract}

\section{INTRODUCTION}

Climate change and its impacts on associated natural and man-made systems have received much scientific attention over the last few decades. In particular, the effects of climate change on regional hydrology are critical because of the physical links between the climate system and the hydrological cycle. Such interactions often cause significant impacts on society, especially in developing regions where natural resources might already be in a state of stress. Water managers and policy makers are looking to the scientific community to provide clarity on how to cope with the additional stress brought about by climate change. While climate change may generally refer to any long-term change in the climate system properties because of natural or forced variability, effects of anthropogenic activities remain of particular concern to the scientific community. Observed patterns of changes in several hydroclimatic variables at large spatial scales are often attributed to human-induced emissions of greenhouse gases and aerosols. Changes in the climate system in turn result in regional modifications in water availability, evapotranspirative water demands of crops and vegetation, extremes of floods and droughts, water quality, salt water intrusion in coastal regions, groundwater recharge and other related processes.

For a developing country such as India, climate change in conjunction with other changes, such as rapid urbanization and industrial growth, has serious implications for policy and infrastructural growth in the water and related sectors. It cannot be denied that urbanization and development in the country are an irreversible reality and are essential to improve the overall quality of life. An immediate impact of climate change on urban water systems is through altered surface water and groundwater resources, because of possible reduction in streamflow and rainfall. Additionally, increasing intensities of rainfall along with unplanned development of cities aggravate the already critical urban flooding problem and stress the urban water infrastructure.

For efficient management of available water resources, an accurate and comprehensive assessment of how the water scenario is likely to evolve is necessary. Water managers are faced with the challenge of evolving adaptive responses and action plans in the face of not only a large uncertainty associated with the projected impacts, but also a sense of perplexity created because of conflicting views, opinions and even scientific projections on the impending regional water 
scenarios. Such a sense of confusion is particularly pronounced in India, where the capacity to understand the different aspects of climate change as it affects the water systems is extremely limited among water managers. Availability of quality-controlled long records of observed data for different hydrological variables also remains an area of concern.

For impact assessment studies and reliable future simulations, scientists have to rely on models. For example, the General Circulation Models (GCMs) provide numerical simulations of the global climate system, while hydrological models are physically-based numerical models for simulating regional hydrological processes. The GCMs tell us, with some confidence, how the climate is likely to evolve in future, while the hydrological models help us capture natural processes related to water, such as flow of water in a stream, evaporation from the land surface, evapotranspiration from crops and vegetation, groundwater movement and recharge, soil moisture, and sediment and pollutant transport in streams. The GCMs provide a range of plausible future projections taking into account a broad, large-scale view of evolution of climate under external forcings (Kundzewicz et al. 2008, 2009), especially the changes of greenhouse gases in the atmosphere. These projections of climate variables are further used to obtain regional changes, such as those in precipitation and evapotranspiration; such studies are typically termed "climate change impact assessment studies". Not only do the GCMs operate at coarser scales compared to those typically required in impact studies, but their performance is also known to reduce from climate variables, such as temperature, wind speed, humidity and air pressure, to hydrological variables such as precipitation, runoff, soil moisture and evapotranspiration (Wilby et al. 1998). Thus, the direct use of GCM outputs in regional water resources impact assessment studies is restricted.

To address this scale and physical processes mismatch between the GCM outputs and regional hydrological variables, impact assessment studies routinely employ techniques that are collectively known as downscaling methods (Wilby and Dawson 2013). Statistical downscaling involves fitting a relationship between historically observed hydrologic predictands and large-scale atmospheric predictors. Future large-scale climatic variables from GCM simulations are then fed into these relationships to estimate the corresponding local hydrological variables. It is to be noted here that statistical downscaling assumes stationarity of the developed relationship, i.e. the relationship between the predictors and predictands remains unaltered in changed scenarios.

For Indian rivers, Gosain et al. (2006) analysed the effects of climate change using daily weather data from a regional climate model along with a distributed hydrological model, namely SWAT (Soil and Water Assessment Tool). They conclude that under an increasing greenhouse gas scenario, the severity of droughts and intensity of floods in various parts of the country are likely to increase. The river basins of Cauvery, Ganga, Narmada and Krishna may experience seasonal or regular water-stressed conditions, while those of Godavari, Brahmani and Mahanadi are predicted to face severe flood conditions, though they may not have water shortages. Impact assessment studies such as those cited above suffer from several uncertainties resulting from the choice of GCM, greenhouse gas emissions scenario, downscaling methods and hydrological models. Regional projections from a climate model run under some scenario will thus represent a single trajectory among a number of possible realizations. Uncertainties in those future projections are thus critical for adaptation and it is also necessary to develop methodologies for addressing them. Typically of interest to water policy makers are weighted mean projections obtained by assigning weights to the climate model simulations.

While a growing number of impact assessment studies use numerical simulations of the climate system under the influence of increasing anthropogenic emissions, it is also necessary to assess whether, or to what extent, the observed changes in regional hydrology are likely to be resulting from the natural internal variability of climate alone, or can be explained by external forcings, especially human-induced emissions. Detection and attribution (D\&A) presents a formal way of establishing whether the observed changes are artefacts of a specific forcing but is seldom applied in the context of local hydrological changes. If the past is proven to be affected by humaninduced changes, the credibility of the future projections, based on such changes, increases. 
However, if there are uncertainties or lack of confidence in the attribution of observed changes in the past, one has to consider similar uncertainties in the future projections as well.

This paper summarizes findings from some recent studies on impacts of climate change on water availability, water quality and irrigation demands, including uncertainty quantification and modelling, as well as investigation of causes of observed changes in regional hydrology. These aspects, as discussed above, are extremely important for sustainable water resource management under climate change. Streamflow in the Indian river basins of Mahanadi and Tunga-Bhadra are considered for the illustration of applications of some of the developed techniques. The results are discussed focusing on implications of climate change for Indian regions.

\section{WATER AVAILABILITY UNDER CLIMATE CHANGE}

Basin-scale water availability under climate change remains of particular concern to water managers and needs to be properly assessed. For the Mahanadi River basin, one of the largest rivers in the eastern part of the country, Ghosh and Mujumdar (2008) report a decrease in monthly flows. It is found that although there is no significant change in the median of the monsoon flows, the occurrence of high flows is likely to reduce significantly due to high surface warming and, therefore, there is a decreasing trend in the monthly peak flows. One reason for such behaviour could be the insensitivity of climate variables towards low flows because of a significant groundwater component in the low flows so that the effects are reflected only on the high flows. Quantifying such a decrease in water availability is critical for the Hirakud Reservoir in the Mahanadi basin, to plan how to meet future water demands.

The flow duration curves for monsoon streamflows in the Mahanadi River for current and future time slices of 2045-2065 and 2075-2095 are shown in Fig. 1, as reported by Raje and Mujumdar (2010). These flow duration curves specify the flow that may be exceeded at a given level of probability and are likely to be used in the hydrological design of dams, bridges, culverts, stormwater drainage networks, etc. Figure 1 shows that there is a decrease in the mid-level flows (flows that are exceeded 30-70 percent of the time) for most future scenarios, because of the likely decrease in rainfall over the region. It is thus important that the future water-use policies are designed to take care of the likely deficit. While the high flows are predicted to increase for most scenarios for 2040-2065, the low flows (flows that are exceeded 80 percent of the time) show a slight increase for 2040-2065, and a smaller range of low flows increase for 2075-2095 (above 90 percent flows only). This information is necessary for developing the optimal reservoir operating policies to maintain the reliability of hydropower generation at the current level, considering the trade-offs between hydropower, irrigation and flood control. It can also be noted that the direction of change in the streamflow projected by different models may be different - that is, some models project an increase while others project a decrease in streamflow. To provide the policy makers with alternative adaptive responses, addressing such uncertainties is both necessary and challenging.
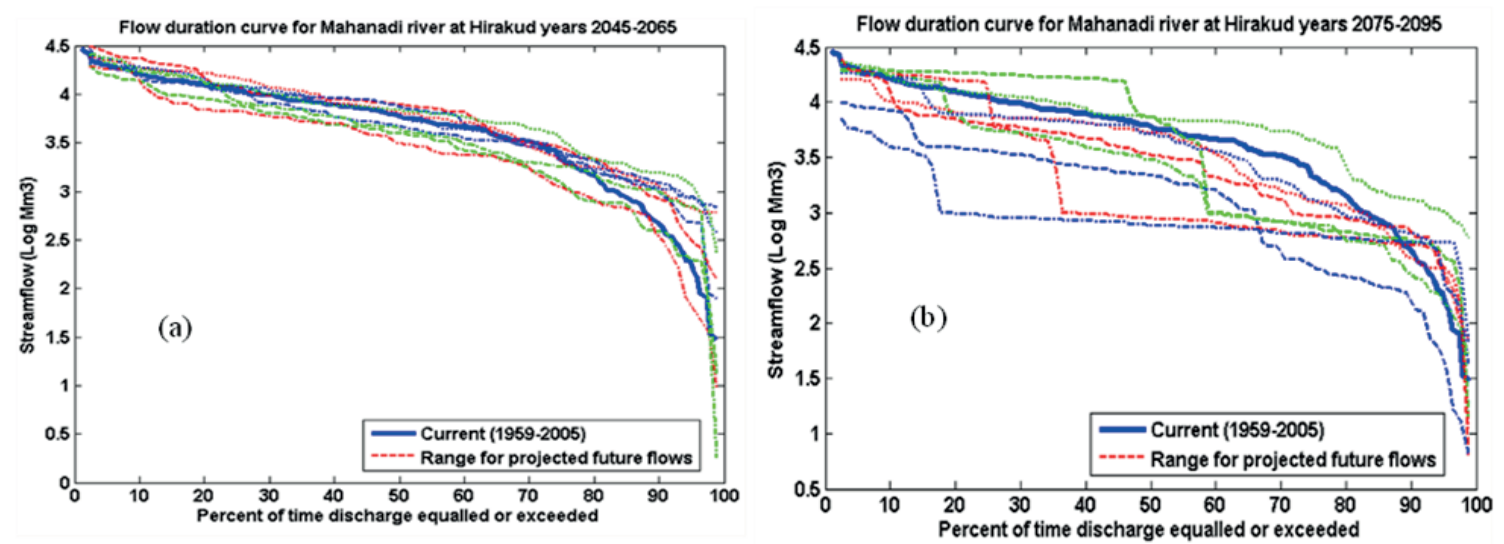

Fig. 1 Flow duration curves for Mahanadi River for current and future time slices (source: Raje and Mujumdar 2010). 
Raje and Mujumdar (2010) also show that the optimal operation involves a decrease in hydropower and increase in vulnerability in the future under climate change. Additionally, they report that by marginally sacrificing reliability with respect to irrigation and flood control, hydropower reliability and generation can be increased for future scenarios. Overall, climate change is likely to affect reservoir performance significantly and future reservoir operation policies are unlikely to restore past performance levels.

Meenu et al. (2013) assess the impacts of climate change on the hydrology of the TungaBhadra River using the statistical downscaling tool SDSM (Statistical Downscaling Model) version 4.2 to obtain the maximum and minimum temperature and daily mean areal precipitation in the four sub-basins of the river. The statistically downscaled temperature and precipitation projections were fed into the physically-based HEC-HMS (Hydrologic Engineering Center's Hydrologic Modeling System) hydrologic model version 3.4, to obtain the future projections of streamflow at the outlet of the basin. Streamflow in the Tunga-Bhadra River was predicted to increase by $46 \%$ by the 2080 s in accordance with increase in precipitation projections of $28 \%$ by the HadCM3 (the Hadley Centre Climate Model) GCM for the A2 emissions scenario. It is thus observed that projections of water availability in different rivers across the country do not follow any uniform pattern; fine-scale impact assessment studies are therefore necessary to mitigate regional impacts of climate change.

\section{WATER QUALITY UNDER CLIMATE CHANGE}

River water quality is affected by increase in water temperature which drives the rates of biological and chemical processes through influences on the reaction kinetics. Reduction in the dissolved oxygen (DO) concentration because of increasing temperatures directly affects the selfpurification capacity of the river system. The other important factor influencing river water quality is streamflow, which defines the rate of pollutant transport and dilution of pollutant loads. Low water quality (LWQ) risks under future climate change scenarios are quantified by Rehana and Mujumdar (2012), who assessed the impacts of climate change for river water quality management in the Tunga-Bhadra River basin. To arrive at local future estimates of hydro-climatic variables that influence river water quality (inflow, rainfall, maximum and minimum temperatures, relative humidity and wind speed), they used a multi-variable statistical downscaling model involving principal component analysis and Canonical Correlation Analysis (CCA). Such local projections were fed as input to a water quality simulation model, QUAL2K. Future projections from the Model for Interdisciplinary Research on Climate (MIROC) 3.2 medium-resolution GCM with the A1B scenario showed increasing trends of temperature variables and minor changes of wind speed and relative humidity in this river basin. Predictions of water quality threshold exceedence for DO were obtained from the projections of streamflow and water temperature. The climate change induced LWQ risk is defined as the occurrence of LWQ for a specified threshold.

Projected streamflows in the Tunga-Bhadra River were found to be significantly decreasing at various locations along the river resulting in decreasing DO levels, assuming unaltered effluent loadings. The observed and future simulated DO levels for 30-year time slices (2010-2040, 2040-2070 and 2070-2100) at two check points (numbered 1 and 10) are shown in Fig. 2. The remaining check points along the river also show significant decrease in DO levels. In fact, future DO levels are found to be decreasing even at certain check points that are not immediately downstream of any discharge. This is because of the reduced dilution capacity and low velocities resulting from reduced streamflow, and changes in reaction rates due to increase in water temperature. Bounds of the LWQ are also projected to increase for this river. Moreover, a significant decrease is also observed historically in the river flows, along with an increase in temperature in the region, thereby emphasizing the importance of the ensuing water quality risks and necessary adaptation measures. 


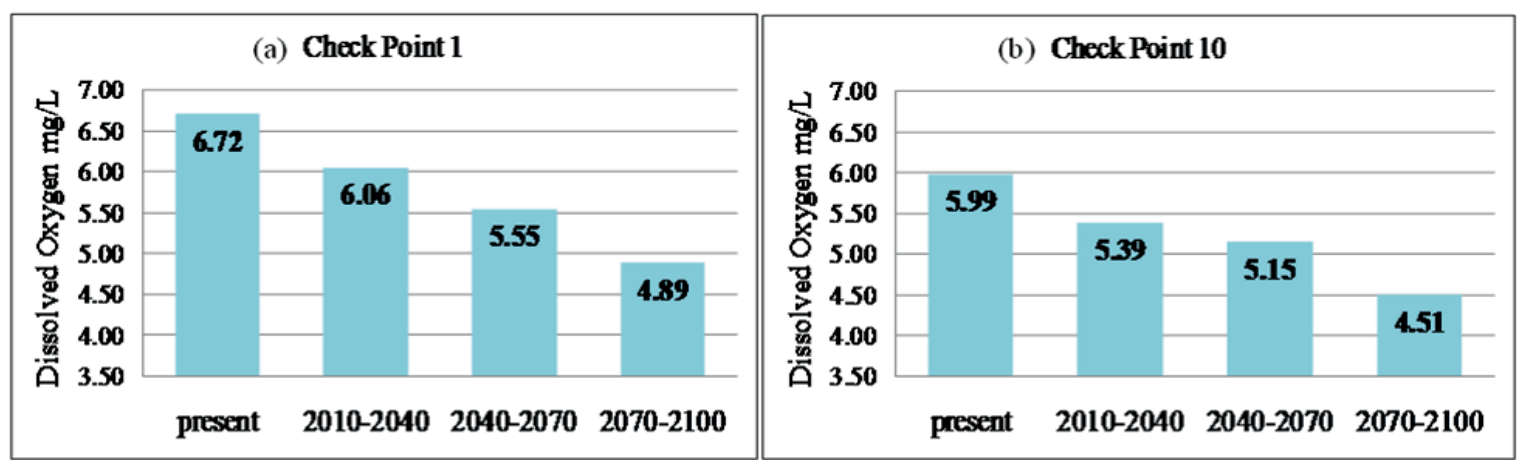

Fig. 2 Present and future DO-level estimates at two check points along the Tunga-Bhadra River (source: Rehana and Mujumdar 2012).

\section{IRRIGATION WATER DEMAND UNDER CLIMATE CHANGE}

Global climate change is likely to result in changes in crop water demand, thus affecting agriculture. Changes in temperature and precipitation patterns because of rising levels of atmospheric carbon dioxide alter evapotranspiration demand and therefore affect water availability and crop production. The type of crop, cropping pattern, crop season, growth stage of the crops, soil type, topography, precipitation, temperature, humidity, wind velocity and intensity of sunlight affect the irrigation water requirement. Changes in climatic characteristics may alter crop water demands even without any change in the cropping pattern. Rehana and Mujumdar (2013) analysed future changes in irrigation demands of crops under climate change by integrating a climate change projection model, an irrigation demand model and an evapotranspiration model. For the Bhadra command area in the southern part of India, future projections of rainfall and other meteorological variables were obtained by using a CCA-based multivariate statistical downscaling model, with the MIROC 3.2 medium resolution GCM for the A1B scenario. The monthly rainfall was projected to increase over this region. The reference evapotranspiration was also projected to increase following increases in future maximum and minimum temperatures and relative humidity. The Penman-Monteith model was used to obtain the evapotranspiration projections. The computed monthly reference evapotranspiration was adjusted with individual crop coefficients to compute the potential evapotranspiration for each crop, which in turn was used to obtain the irrigation water demand of the crop. The crop water demands of paddy, sugarcane, permanent garden and semi-dry crops were projected over the Bhadra command area.

The annual irrigation water requirements of these crops for nine locations encompassing the Bhadra command area are shown in Fig. 3. The crop water requirements of paddy and sugarcane are in general higher compared to those of permanent garden and semi-dry crops because of the cropping pattern in the command area. Though the projected crop water demands are higher than those observed historically, the relative differences between the future demands are small, owing to the projected increase in rainfall. These projected crop water demands will serve as a guideline for the water managers for accommodating sufficient water in those months where rainfall alone will not be sufficient to fulfil the irrigation requirements.

It is noted here that the actual evaporation rate would depend on the water availability. In other words, the amount of water stored in the soil is another important factor for agriculture in addition to the rainfall and evaporation and, hence, projections of soil moisture must be included in assessment of irrigation water demands under climate change. Having discussed the methods of obtaining regional hydrological projections necessary for water resources management and the results thereof, for some river basins in the country, the following section focuses on addressing the uncertainties associated with such projections. The topic of uncertainty, as observed from the recent body of scientific literature, seems to be inevitably associated with any analysis on impacts of climate change and therefore needs to be comprehensively addressed. 

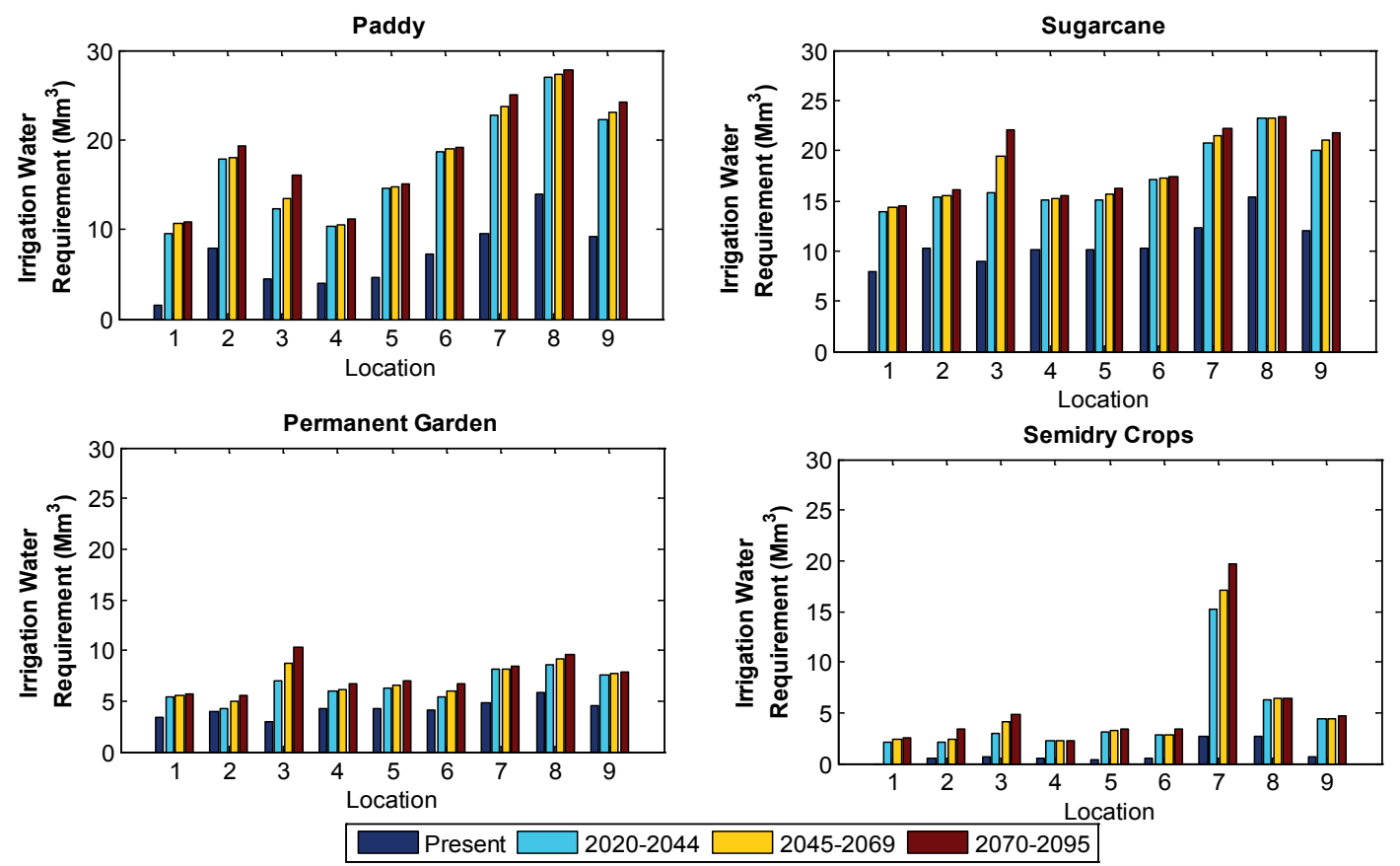

Fig. 3 Historical and projected irrigation water requirements for the Bhadra command area (source: Rehana and Mujumdar 2013).

\section{QUANTIFICATION OF UNCERTAINTY IN HYDROLOGICAL IMPACTS OF CLIMATE CHANGE}

As already elucidated in the first section, regional climate change impact assessment studies suffer from uncertainties resulting from various sources, including limitations in scientific knowledge (for example, effect of aerosols), which can be classified as GCM uncertainty, randomness, and human actions (such as future greenhouse gas emissions) that can be classified as scenario uncertainty. It is a scientific challenge to quantify these uncertainties. We discuss some recent studies that have attempted to model the uncertainty resulting from the use of multiple GCMs and scenarios. One possible way to model these uncertainties is to treat the projected hydrological variable of interest as a random variable resulting from multiple model projections and to obtain its non-parametric probability distribution. Another straightforward method for combining information from multiple GCM-scenario combinations is to weight them equally as they are often deemed to be equally likely. Mujumdar and Ghosh (2008) developed a methodology to model GCM and scenario uncertainty using possibility theory. In this method, the performance of each GCM is first assessed in simulating signals of climate forcing in the recent past and, based on such a performance, possibility values are assigned to model simulations. These possibilistic weights are then used to arrive at the possibilistic mean cumulative distribution function (CDF) for the future scenarios, which is of use to policy makers. Monsoon streamflow in the Mahanadi River at the Hirakud Dam was chosen as the variable under consideration.

Large-scale climatic predictors from three GCMs - the Centre for Climate System Research/National Institute for Environmental Studies (CCSR/NIES) model, the Hadley Centre Climate Model 3 (HadCM3) model and the Coupled Global Climate Model 2 (CGCM2) model with two emissions scenarios, A2 and B2, are used in the study. The cumulative distribution functions (CDFs) of the monsoon streamflows resulting from using these GCM-scenario combinations are presented in Fig. 4. Figure 4 reveals a considerable disagreement between the simulations of GCMs for medium flow in the observed period. A significant dissimilarity is also evident amongst the projections for the GCMs and scenarios. To model the resulting uncertainty, possibilities are assigned to GCMs and scenarios based on their performance in predicting the 

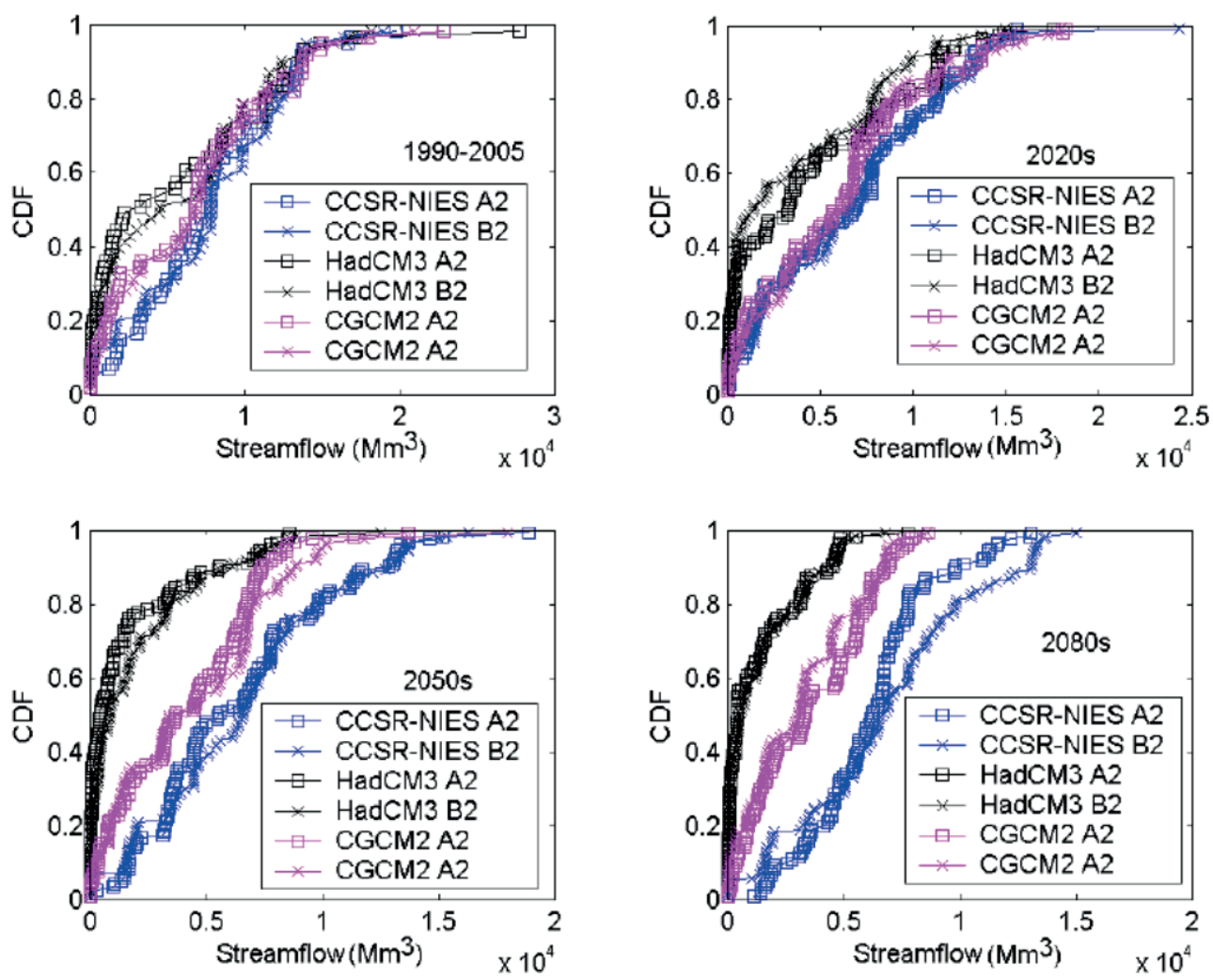

Fig. 4 Cumulative distributions of monsoon streamflows in the Mahanadi River from different models and scenarios (source: Mujumdar and Ghosh 2008).

Table 1 Uncertainty in projections of Mahanadi streamflows (million cubic metre) at Hirakud Dam (source: Mujumdar and Ghosh 2008). LB = Lower bound; UB = Upper Bound; CDF = Cumulative probability distribution.

\begin{tabular}{|c|c|c|c|c|c|c|c|c|c|}
\hline \multirow{4}{*}{$\begin{array}{l}\text { CDF } \\
\text { value }\end{array}$} & \multicolumn{9}{|c|}{ Quantile [Streamflow $\left(\times 10^{6} \mathrm{~m}^{3}\right)$ ] } \\
\hline & \multicolumn{3}{|l|}{$2020 \mathrm{~s}$} & \multicolumn{3}{|c|}{$2050 \mathrm{~s}$} & \multicolumn{3}{|l|}{$2080 \mathrm{~s}$} \\
\hline & UB & LB & Difference & UB & LB & Difference & UB & LB & Difference \\
\hline & $\mathrm{CDF}$ & $\mathrm{CDF}$ & & $\mathrm{CDF}$ & $\mathrm{CDF}$ & & $\mathrm{CDF}$ & $\mathrm{CDF}$ & \\
\hline 0.25 & 131 & 2732 & 2601 & 63 & 3524 & 3461 & 76 & 4508 & 4433 \\
\hline 0.50 & 1381 & 6807 & 5426 & 393 & 6576 & 6183 & 491 & 6690 & 6199 \\
\hline 0.75 & 7329 & 10144 & 2815 & 1639 & 8623 & 6984 & 1638 & 9120 & 7482 \\
\hline 0.90 & 9811 & 13412 & 3601 & 5584 & 13009 & 7425 & 3375 & 13070 & 9695 \\
\hline 0.95 & 11313 & 15482 & 4169 & 7395 & 13667 & 6272 & 4675 & 13263 & 8586 \\
\hline
\end{tabular}

streamflow for the recent past (1991-2005) that may contain climate change signals. These possibilities were used further to obtain the possibilistic mean future CDFs. Table 1 presents a summary of the uncertainty analysis and shows the streamflow quantiles derived from the upper and lower bounds of the CDF and the difference between them corresponding to different cumulative probabilities for three future time periods. It is observed that for a given CDF value, the uncertainty increases with time because of different climate sensitivities among the models.

It is worth noting that the choice of downscaling method may introduce another source of uncertainty arising from 'incomplete' or 'imperfect' information. Such an uncertainty might propagate through the climate change impact assessment in an inter-dependent, but not necessarily additive or multiplicative manner. Also, other approaches exist for addressing the uncertainties arising out of using multiple GCMs and emissions scenarios involving weighting the models and scenarios with respect to their agreements on future projections (such as that of Ghosh and Mujumdar 2009) using reliability ensemble averaging (REA). The principal aim in any such study, as discussed above, is to quantify the risks of meeting water demands in terms of the uncertainty bounds. 


\section{DETECTION AND ATTRIBUTION OF HYDROLOGICAL CHANGE}

We have discussed so far, several techniques for obtaining reliable regional hydrologic projections corresponding to different evolutions of the climate system under external forcings, in particular that of anthropogenic emissions. However, it is also necessary to examine whether the signals of such forcings can indeed be discernible in regional hydrological observations. As mentioned earlier, detection and attribution studies offer a means of addressing such problems. According to the IPCC (2010), Detection of change is defined as the "process of demonstrating that climate, or a system affected by climate, has changed in some defined statistical sense, without providing a reason for that change'. Attribution, on the other hand, is defined as the 'process of evaluating the relative contributions of multiple causal factors to a change or event with an assignment of statistical confidence'. Several components of the climate system, at large scales, are already shown to contain signals of human-induced greenhouse emissions (Bindoff et al. 2013), over and above changes expected due to natural internal variability of climate alone, and are inconsistent with changes expected from other external causes such as solar or volcanic activities. Regional D\&A applications, especially for hydrological change at local scales, addressing the physical process and scale mismatch issues, are rare.

The pattern correlation-based fingerprint method of D\&A is used by Mondal and Mujumdar (2012) for detection and attribution of human-induced climate change in monsoon precipitation and streamflow over the Mahanadi River basin. The fingerprint defines the direction in which the human-induced signal is expected to lie. This method reduces the detection problem to a univariate or low-dimensional problem in the detection variable. In this low-dimensional space, the human-induced climate change 'signal' in the observations and the natural internal climate variability 'noise' are statistically contrasted, and the detected vector is further compared with the vector obtained from the expected climate change pattern. The effects of internal climate variability and external anthropogenic or natural forcings, such as solar and/or volcanic activities, are estimated from statistically-downscaled river basin-scale hydrological variables using corresponding large-scale climate variables from long, pre-industrial control runs (noise), or anthropogenically-forced 20th century runs (anthropogenic signal), or solar and/or volcanicallyforced historical runs, respectively, from each of multiple climate models. A principal component analysis and linear regression based statistical downscaling model is used to obtain the local precipitation, while a genetic programming based rainfall-runoff model is additionally employed to arrive at the streamflows in the river basin corresponding to each run of the controlled climate modelling experiments. Similar to the statistical downscaling models discussed in previous sections, these models are essential to address the scale and physical processes mismatch between large-scale climate model simulations and regional hydrological observations.

Figure 5 presents the detection plot for the monsoon streamflow for the Mahanadi River basin. The observations show a positive signal, which does not include zero, at the $95 \%$ statistical confidence level. It is also consistent in sign with signal strengths of anthropogenically (ANTH) forced runs of several GCMs (shown in blue). The multi-model ensemble-averaged anthropogenic signal strength is found to be consistent with the observed signal strength. However, attribution is not unique in this case, as the solar-volcanic signal strength (that is, the evolution of the hydroclimatic system considering simultaneous changes in solar irradiance and volcanic activities, but excluding human emissions) is also found to be similar to the observed signal strength. In particular, the GCMs shown in cyan have poor performance as far as basin-scale monsoon streamflow is considered in this region because their anthropogenic signal strengths are opposite in sign to that from the observations. For several GCMs, the anthropogenic climate change signal is found to be embedded in natural internal climate variability. At smaller scales, the problem of attribution is thus particularly challenging because of large natural variabilities. The timeevolution of the S/N ratio, as shown by Mondal and Mujumdar (2012), reveals that for this river basin, earlier detection is achieved in monsoon streamflows as compared to monsoon precipitation. In general, detection is reported to be more conspicuous in streamflow as compared to precipitation, for this river basin. 


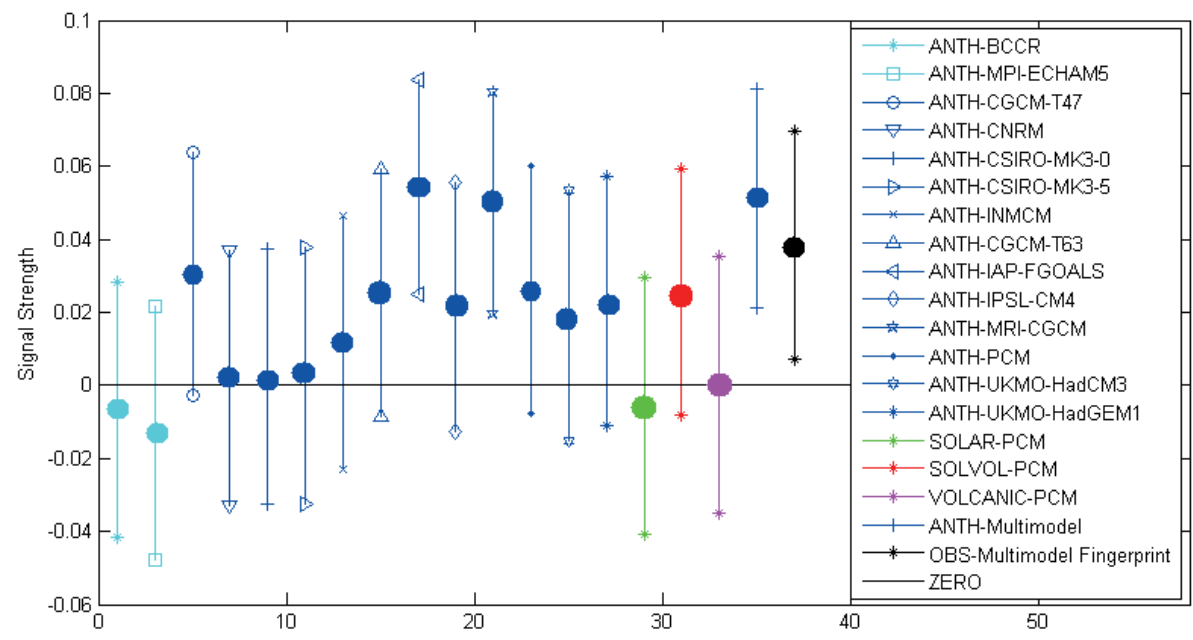

Fig. 5 Detection plot for monsoon streamflow in the Mahanadi River (source: Mondal and Mujumdar 2012). The ensemble-averaged signal strengths ( $\mathrm{S}$ values) from each model run (dots) and their $95 \%$ confidence intervals (bars) are shown. The observed signal strength $\left(\mathrm{S}_{\mathrm{obs}}\right)$ with its $95 \%$ confidence interval, considering the multi-model ensemble-averaged ANTH fingerprint, is shown in black. The GCMs for which the ANTH signal strength is inconsistent in sign with $\mathrm{S}_{\mathrm{obs}}$ are marked in cyan and those for which the ANTH signal strength is consistent with $\mathrm{S}_{\text {obs }}$ are marked in blue.

\section{SUMMARY}

Climate change impacts on regional hydrology are particularly critical for a developing country such as India and are expected to exacerbate the situations in already water-stressed river basins in the country. Projections of the climate system under increasing global temperatures using coarse resolution climate models may be useful at large spatial scales; however, for better management of regional natural resources, impacts need to be assessed at much finer scales. Recent studies have developed methods for reliable regional climate change impact assessments. There is a notable uncertainty associated with the exact nature of impacts on the water sector at local, river basin scales and methodologies are developed to quantify and constrain that uncertainty. In the context of water management, it is the responsibility of the scientific community to communicate the results in a manner that is useful and easy to understand for the policy makers. Analysing the pattern of observed changes in regional hydrological variables is also necessary to investigate the causes of such changes, especially at local scales. Unequivocal detection of the presence of external forcing agents in regional hydro-climatic changes is difficult because of large natural variability at smaller spatial scales. The water management agencies and policy makers must use this information along with the associated uncertainties, while planning for the future.

\section{REFERENCES}

Bindoff, N.L. et al. (2013) Detection and attribution of climate change: from global to regional. In T.F. Stocker et al. (eds) Climate Change 2013: The Physical Science Basis. Contribution of Working Group I to the Fifth Assessment Report of the Intergovernmental Panel on Climate Change. Cambridge, United Kingdom and New York, NY, USA: Cambridge University Press.

Ghosh, S. and Mujumdar, P.P. (2008) Statistical downscaling of GCM simulations to streamflow using relevance vector machine, Advances in Water Resources 31, 132-146.

Ghosh, S. and Mujumdar, P. (2009) Climate change impact assessment: Uncertainty modeling with imprecise probability. Journal of Geophysical Research: Atmospheres (1984-2012), 114(D18), doi:10.1029/2008JD011648.

Gosain, A.K., Rao, S. and Basuray, D. (2006) Climate change impact assessment on hydrology of Indian river basins. Current Science 90(3), 365-371.

IPCC (2010) Meeting report of the Intergovernmental Panel on Climate Change expert meeting on detection and attribution related to anthropogenic climate change. Bern, Switzerland: Univ. of Bern, IPCC Working Group I Technical Support Unit.

Kundzewicz, Z.W. et al. (2008) The implications of projected climate change for freshwater resources and their management. Hydrological Sciences Journal 53(1), 3-10. 
Kundzewicz, Z.W. et al. (2009) Reply to "Climate, hydrology and freshwater: towards an interactive incorporation of hydrological experience into climate research". Hydrological Sciences Journal 54(2), 406-415.

Meenu, R., Rehana, S. and Mujumdar, P.P. (2013) Assessment of hydrologic impacts of climate change in Tunga-Bhadra River basin, India with HEC-HMS and SDSM. Hydrological Processes 27(11), 1572-1589.

Mondal, A. and Mujumdar, P. (2012) On the basin-scale detection and attribution of human-induced climate change in monsoon precipitation and streamflow. Water Resources Research 48(10), W10520.

Mujumdar, P.P. and Ghosh, S. (2008) Modeling GCM and scenario uncertainty using a possibilistic approach: Application to the Mahanadi River, India. Water Resources Research. 44, W06407.

Raje, D. and Mujumdar, P.P. (2010) Reservoir performance under uncertainty in hydrologic impacts of climate change. Advances in Water Resources 33(3), 312-326.

Rehana, S. and Mujumdar, P.P. (2012) Climate change induced risk in water quality control problems. Journal of Hydrology, 444-445, 63-77.

Rehana, S. and Mujumdar, P.P. (2013) Regional impacts of climate change on irrigation water demands. Hydrological Processes 27(20), 2918-2933.

Wilby, R.L. and Dawson, C.W. (2013) The statistical downscaling model: insights from one decade of application. International Journal of Climatology 33(7), 1707-1719.

Wilby, R.L., Hassan, H. and Hanaki, K. (1998) Statistical downscaling of hydrometeorological variables using general circulation model output. Journal of Hydrology 205(1), 1-19. 